
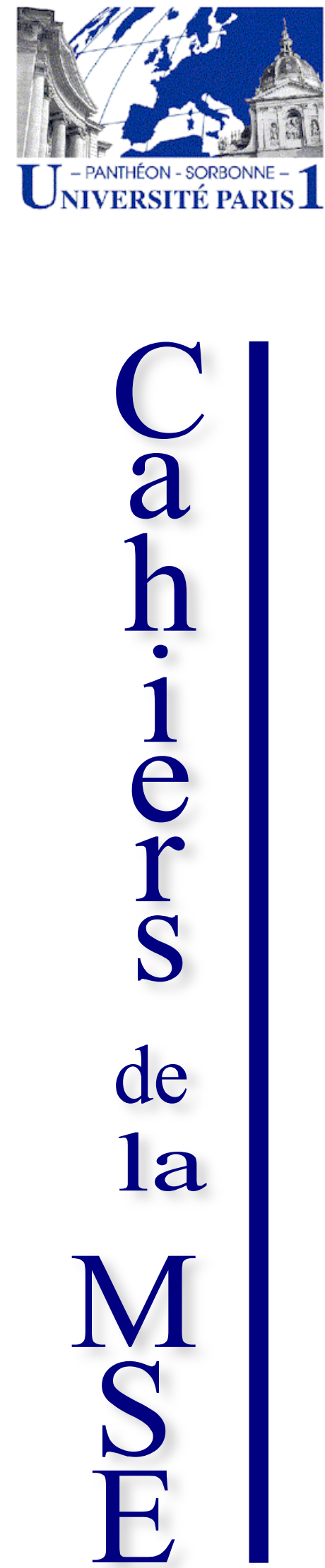

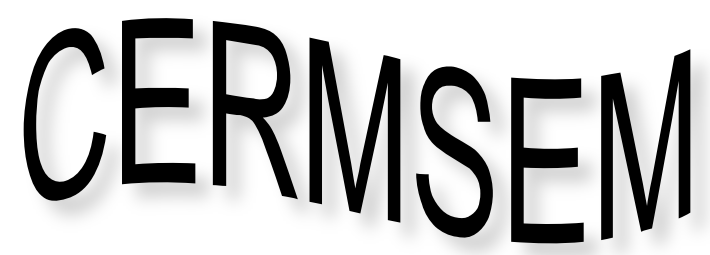

UMR CNRS 8095

An Extension of the Trade Restrictiveness Index to Large Economies

Sami DAKHLIA

Akram TEMIMI

2004.53 


\section{An Extension of the Trade Restrictiveness Index to Large Economies*}

\author{
Sami Dakhlia \\ University of Alabama \\ sami@ua.edu
}

\author{
Akram Temimi \\ University of Alabama \\ atemimi@cba.ua.edu
}

May 9, 2004

*Thanks to Ed Balistreri, Richard Boylan, Walt Enders, Ron Jones, Paul Pecorino, and an anonymous referee for helpful conversations and comments. Correspondence to Sami Dakhlia, Dept. of Economics and Finance, Culverhouse College of Business, Univ. of Alabama, Tuscaloosa, AL 35487-0224, USA. Office: (205) 348-2927. Fax: (205) 348-0590. 


\title{
An Extension of the Trade Restrictiveness Index to Large Economies
}

\begin{abstract}
The Trade Restrictiveness Index (TRI) introduced by Anderson and Neary (1994) provided the first theoretically satisfying measure of a country's tariff structure by overcoming the problem of ad hoc specification of indexing weights and the related index number problem. We observe, however, that the TRI may not exist or may not be unique when countries are large. As a remedy, we propose a simple extension.
\end{abstract}

\section{Measuring trade restrictiveness}

Traditional tariff indices have usually focused on one of three measures: (1) the nominal level of tariffs per class of goods, (2) weighted measures of average tariffs defined as total revenues divided by total value of imports (and various modifications to this basic idea), or (3) measures of effective protection on an item-by-item basis where nominal tariff levels are corrected for tariffs on inputs used in production of these goods. All three suffer from a variety of theoretical and empirical problems. The first measure ignores the relative importance of a good in total trade, the second has serious problems with respect to trade weights, given the problem that a nearly prohibitive tariff might add little to the revenues received, and the third is not only problematic when used to create an overall index but also suffers from the fact that effective protection measures ignore the costs of tariff restrictions to the consumer. The most widely cited recent attempt to create a more universal tariff measure is the Trade Restrictiveness Index (TRI) first promoted by Anderson and Neary (1994).

To overcome the index number problem, Anderson and Neary (AN) look for the uniform tariff equivalent (UTE); that is, the ad valorem tariff rate $u$ that when applied to all imports would inflict upon its citizens the same welfare loss as the actual system of ad valorem tariffs $\left(t_{1}, \ldots, t_{i}, \ldots\right) .{ }^{1}$ Formally, find $u$ such that

$$
V\left(t_{1}, \ldots, t_{i}, \ldots\right)=V(u, \ldots, u, \ldots),
$$

\footnotetext{
${ }^{1}$ Their TRI is the inverse of 1 plus the UTE.
} 
where $V$ is the representative consumer's indirect utility function.

The UTE is thus a theoretically exact tariff aggregator by virtue of being derived from utility considerations and, as such, is superior to aggregators based on ad hoc indexing weights. ${ }^{2}$ The beauty of this approach is that it examines our motivation behind the quest for a measure of trade restrictiveness. The answer, that we care about trade restrictions because they affect our well-being, provides the solution to our measurement problem: find a tariff aggregate with the same welfare effect as the actual trade restricting policy.

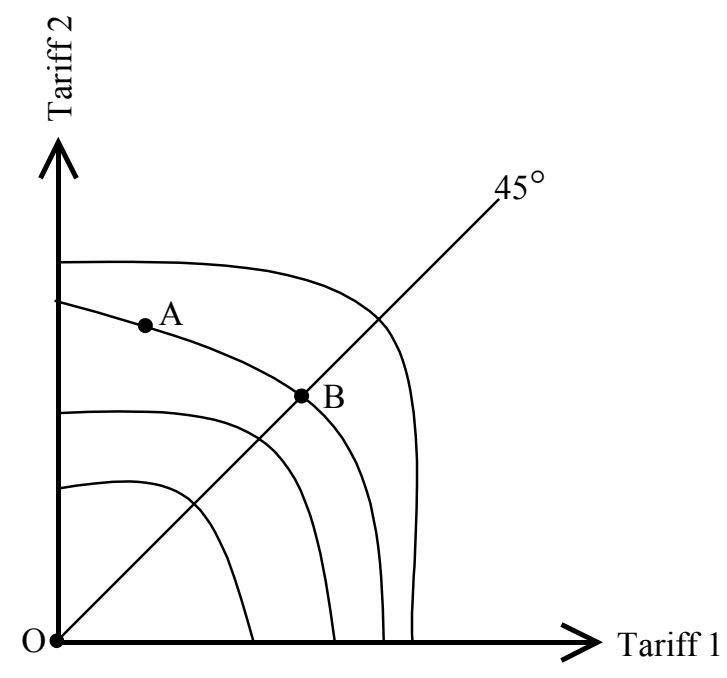

Figure 1: The Uniform Tariff Equivalent

The UTE is illustrated in Figure 1, showing the country's welfare level curves with respect to ad valorem tariff rates on two goods. If the actual tariff structure is represented by point $\mathrm{A}$, then point $\mathrm{B}$ represents the uniform tariff rate vector with the same (negative) welfare effect. ${ }^{3}$

\footnotetext{
${ }^{2}$ Anderson and Neary's Trade Restrictiveness Index also allows for quota-constrained goods. For the purposes of this paper, however, we can restrict our attention to a simplified TRI dealing with ad valorem tariffs only.

${ }^{3}$ In order to derive the index, the economy must be explicitly modeled in a general equilibrium framework. In practice, a computable general equilibrium (CGE) model must be specified and calibrated using the available historic data as well as many assumptions on preferences and technology. The index number problem is thus replaced by a debate over
} 
We emphasize that this approach must necessarily assume that the country is small. Since a large country may have a non-zero optimal tariff, the welfare effects are no longer monotonic in uniform tariffs. This, in turn, implies that, generically, if the small-country assumption is dropped, the UTE would either not exist or would take multiple values. This intuition is illustrated in Figure 2.

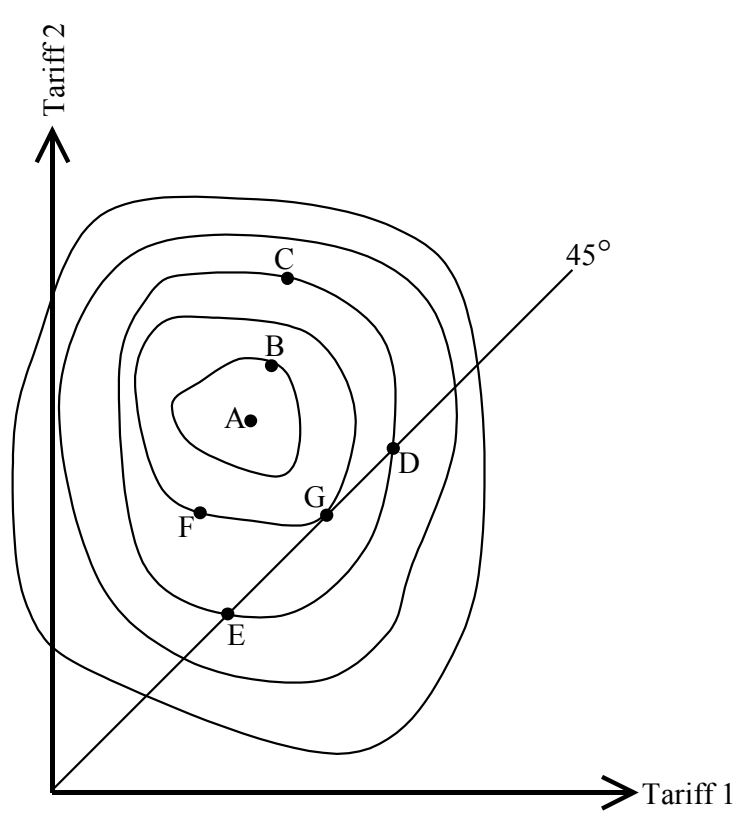

Figure 2: Non-existence or multiplicity of a UTE

In the large-country case, the welfare-maximizing tariff vector, represented by point $\mathrm{A}$, is in the positive orthant and the welfare level curves are concentric around the optimum. ${ }^{4}$ We can now visualize three cases:

1. Let the actual tariff vector be given by point $\mathrm{B}$; it is located on an iso-welfare curve that does not intersect the 45 degree line; hence, a UTE does not exist;

the correct specification of the CGE model, in particular over the elasticities of substitution both in preferences and in technology, a point made forcefully by O'Rourke (1997).

${ }^{4} \mathrm{We}$ are not claiming that the iso-welfare curves are necessarily well-behaved, or even that point A is the only local welfare maximum: indeed "better-than" sets need not always be convex. In the presence of such "pathologies", however, issues of non-existence or multiplicity can only get more severe. 
2. Let the actual tariff be given by point $\mathrm{C}$, located on an iso-welfare curve that intersects the 45 degree line at points $\mathrm{D}$ and $\mathrm{E}$; there are thus multiple UTEs;

3. Finally, let the actual tariff be given by point F with UTE at point G. This case, however, appears to be accidental.

Mathematically, the source of the problem is that a country's own welfare is not monotonic over the set of positive tariffs. Whereas in the small-country case we were able to gauge protection solely by the degree of a country's selfinflicted harm, we must now seek a revised measure of trade restriction.

\section{An alternative}

In our quest for an unambiguous measure of protection, it is helpful to remember that three motives can generally be associated with trade restrictions: the need for revenue collection (in particular in countries with large underground economies where sales taxes are impractical and ineffective), potential improvements of terms-of-trade, and pressure from special interest groups. Clearly, not all of these motives are necessarily injurious to national welfare. While tariffs restrict trade, not every tariff scheme is necessarily a concession to lobbies aimed at protecting one domestic producer at the expense of another. Restriction is not limited to just protectionism.

To measure the cost of protectionism, that is, the cost to national welfare of shielding some domestic firms from the rigors of worldwide competition, we need to compare actual national welfare to an appropriate benchmark. In the general case of a large, revenue-collecting country, the benchmark is given by the welfare-maximizing tariff structure, not the vector of zero tariffs. It is therefore the deviation from the optimal tariff vector that may be identified with bona fide "protection." This distinction is in the spirit of Grossman and Helpman (1995), for example, who decompose tariffs to evaluate the political clout of lobbyists.

Consider Figure 3, which illustrates the case of a large country: the optimal tariff vector $\left(t_{1}^{o p t}, t_{2}^{o p t}\right)$, represented by point $W$, is in the positive orthant, and the iso-welfare curves are concentric around $W$. Let $A$ represent the actual tariff vector. By defining protection as the deviation from the welfare-maximizing tariff vector, the measure of protection continues to be a function of its welfare cost relative to a welfare optimum. An intuitive 


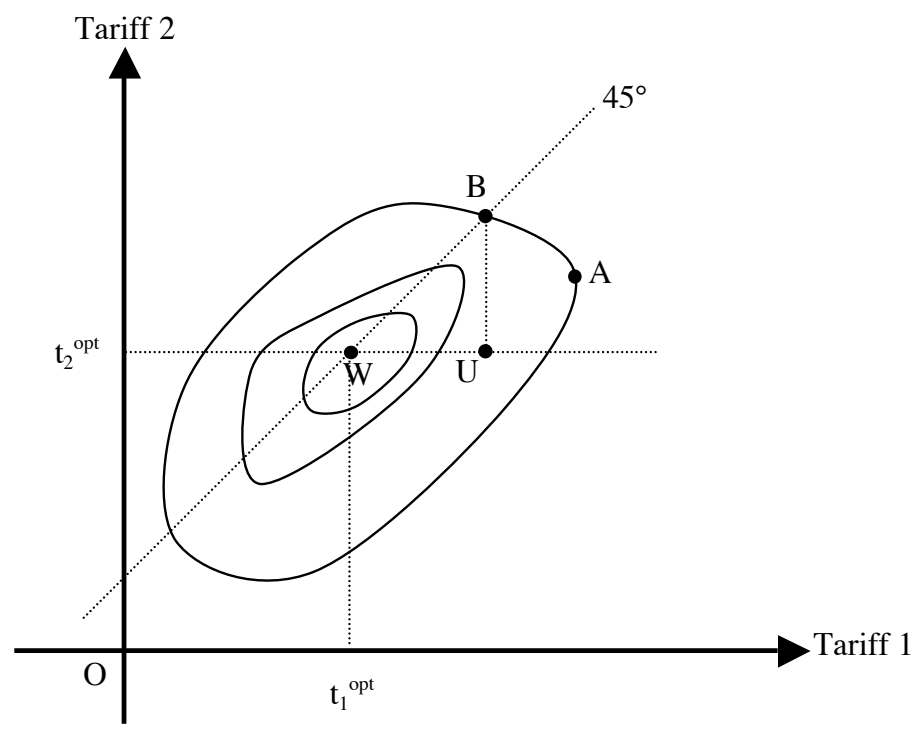

Figure 3: Large country

index of protection could accordingly be called a Uniform Tariff Deviation Equivalent (UTDE). Here, distance $(W, U)$, the projection of distance $(W, B)$, defines the UTDE of tariff $A$. Formally,

$$
V\left(t_{1}^{o p t}+d t_{1}, t_{2}^{o p t}+d t_{2}\right)=V\left(t_{1}^{o p t}+d u, t_{2}^{o p t}+d u\right)
$$

where $d u$ is our measure of protection.

\section{Conclusion}

Our proposed extension of Anderson and Neary's Trade Restrictiveness Index aims to restore the measure's meaningfulness in the case of large economies and does so by distinguishing among the various motives for trade restriction. In essence, because the TRI is calculated on the basis of self-inflicted losses, it is necessary to first account for the welfare-enhancing effects of tariffs, such as revenue motives and improving terms of trade.

An alternative and concise way to present our argument follows. When designing a tariff index on the basis of self-inflicted losses, only two of the following three desiderata can be satisfied simultaneously: 
- D1: The index should be equal to zero when all tariffs are zero; in other words, free trade ought to be the benchmark.

- D2: The index should exist and be unique; in other words, it should be clearly defined and unambiguous.

- D3: The index should be applicable to all countries, regardless of size.

Anderson and Neary's Trade Restrictiveness Index satisfies D1 and D2, but not D3, whereas our proposed modification satisfies D2 and D3, but not D1. Because unfettered free trade must be abandoned as the benchmark of non-restrictiveness, our modification appears to come at a price. To the extent, however, that we are seeking a measure of suboptimality in tariff policy, not a measure of departure from free trade, we view this as a small price to pay. Indeed, our extension might provide a more accurate assessment of the true cost of protectionism, for instance, when studying the link between domestic trade policy and growth.

Free-trade criterion D1 may have ideological and focal point value in multilateral trade negotiations; it may also matter to the extent that country A's tariffs affect country B's welfare. This, however, is not in the spirit of the Trade Restrictiveness Index, which focuses only on self-inflicted losses.

\section{References}

[1] Anderson, James E. and J. Peter Neary, "Measuring the restrictiveness of trade policy", The World Bank Economic Review, 8 (1994) 151-69.

[2] Anderson, James E. and J. Peter Neary, "A New Approach to Evaluating Trade Policy", Review of Economic Studies, 63 (1996) 107-25.

[3] Grossman, G.M. and E. Helpman, "Trade wars and trade talks", Journal of Political Economy, 103 (1995) 675-708.

[4] O'Rourke, Kevin, "Measuring protection: a cautionary tale", Journal of Development Economics, 53 (1997) 169-83. 